\title{
Transition From Textbook to Digital Delivery
}

\author{
John Blake
}

University of Aizu

jblake@u-aizu.ac.jp

\begin{abstract}
This paper describes, explains, and evaluates the transformation of a text-based course into a multimodal, open-access course website. Based on an extensive needs analysis, a course website was selected to house materials for a tailormade thesis writing and presentations course for computer science majors. The theoretical underpinnings based on language, learning, and learners' beliefs were formulated. One of the core concepts was the desire to develop learner autonomy. With this pedagogic base, the course units' scope, focus, and objectives were decided, and then the course content was created. Some practical website design concepts, including the separation of content, styling, and behaviors, are discussed. Extensive usability testing was conducted using focus groups to identify potential improvements to the website's readability and usability. Since its initial release, both course tutors and learners have positively evaluated this course website. The currently deployed version is a user-friendly, learner-friendly website that is easy to maintain and update. Future work will focus on improving learner engagement and improving the user experience.
\end{abstract}

Keywords: online course development, learner autonomy, website development, readability, usability

\section{INTRODUCTION}

Recent advances in wifi availability [1] combined with the increased affordability of mobile devices mean that more people than ever have access to the internet. In Japan, almost all university students have a wifienabled smartphone [2]. People in many parts of the world connect to the internet multiple times daily via their smartphones. According to a survey of smartphone usage in Japan, teenagers $(n=208)$ and young adults $(n=420)$ spend slightly over three hours per day using their smartphones [3].

The coronavirus pandemic that has plagued 2020 has infected 75 million people worldwide (as of 18 December 2020) [4] with a mortality rate of between 1 and $7 \%$ [5]. Social distancing, mask-wearing, and other methods to reduce potential transmission were introduced. In Japan, almost all university students have access to the internet, and most either own or are able to loan laptops from their university. Students were required to attend classes for credit-bearing courses on campus in almost all Japanese universities. However, this requirement's relaxation enabled universities to deliver courses more flexibly. To prevent the spread of COVID-19, universities and schools have turned to the virtual classroom and online learning in place of classes on campus.
For some teachers, this transition was not of their own volition but was coerced by university administrators. This article describes a transition from textbook teaching to digital delivery for an elective credit-bearing course prior to the pandemic. This procedure was subsequently applied to multiple courses early in 2020 in response to the university mandated delivery of courses online.

The main focus of this article is on a thesis writing and presentation course taught by approximately ten professors. This course used to be compulsory but is now offered as an elective. This resulted in fewer enrolled students (approx. $40 \%$ of seniors), and consequently, $60 \%$ had no access to the tailormade materials on how to write a thesis. Many enrolled seniors do not attend each class. In order to encourage attendance, materials for each class were distributed unit by unit rather than as a complete textbook at the start of the course. Despite this tactic, attendance varied greatly, which meant that few students received all the tailormade textbook units. The underlying reasons for the low enrolment and sporadic attendance may be related to the research lab, the individual student, or the course itself.

Regardless of the causes of the enrolment and attendance issues, digital delivery can enable the course 
materials to reach a much wider audience. To enable the course to have as much reach as possible, an online open-access course allows students (and teachers) access to all materials regardless of enrolment status or, in fact, institutional affiliation.

This paper describes, explains, and evaluates the transformation of a text-based course into a multimodal, open-access online course. The remainder of this paper is organized as follows. Section 2 describes the background, focussing on the institutional context, needs analysis and requirements specification. Section 3 details the design phase, including the underlying pedagogic principles and the focus on autonomy. Section 4 introduces the principle of separation of content, styles, and behavior and the associated use of HTML, CSS, and JavaScript. Section 5 provides an overview of the development of the course website. Section 6 evaluates the course website. Section 7 concludes the paper with a summary and an overview of future work.

\section{BACKGROUND}

The thesis writing and presentations course is offered at a small public university specializing in computer science and engineering. The university is located in northern Japan. Course participants are students in their final undergraduate semester. The course's remit is to help students draft a graduation thesis and prepare to a presentation on the same research topic, both of which are primarily assessed by their supervisor. A comprehensive needs analysis was conducted at both the curriculum and course levels to more fully understand the needs, wants, and lacks. The results of these analyses were used to create persona descriptions of archetypical users and use cases, i.e., particular examples of how the website is used. These documents were, in turn, used to create a requirements specification.

\subsection{Curriculum-level needs analysis}

An extensive needs analysis was conducted at the curriculum level in which the opinions of contentsubject teachers of computer science were collected and analyzed [6]. The result was a set of task-based syllabi culminating in the thesis writing and presentations course.

Courses can be placed online in numerous ways, such as via a learning management system (LMS) or WordPress. Using a university-administered LMS, such as Moodle [7], is a convenient option, particularly as the technical barrier to entry is low for course creators. At the planning stage of this project, a university-wide LMS was not yet in place, and there were no volunteers from within the faculty teaching this course to manage a server to house an LMS. For this reason, a simple course website rather than a learning management system was selected to house the content of this course.

\subsection{Course-level needs analysis}

Students enrolled in the author's class $(n=15)$ in the previous year's thesis writing were contacted individually, and focus groups of students were asked (in Japanese) for their views. Feedback showed that students who enrolled but did not show up for any class invariably had achieved enough credits and so saw no reason to attend. The desire to write a higher-quality graduation thesis was apparently not the reason for enrolment. Individual meetings were conducted with all professors who taught this course to understand their content and course delivery opinions.

Persona descriptions of archetypical website users were created to enable the course designer to understand the users more fully. In addition, use cases, that is, various specific situations in which users would access and use the website were considered. For example, a user might want to find out how to refer to an original source and the appropriate citation conventions.

\subsection{Requirements specifications}

The needs analyses, persona descriptions, and use cases were used to inform the requirements specification. A course website rather than a learning management system was selected to house materials for a tailormade thesis writing and presentations course for computer science majors.

Based on requests from professors who were reluctant to use an online course, it was necessary to include an option to print out materials. Thus, two modes for the course website were necessary. A web mode, which would be the primary mode, and a print mode, which allows the professors who preferred to distribute printed course materials to students would continue to do so. Web mode and print modes differ dependent on activities. For example, activities that require embedded video or listening do not appear in the print version.

Student requests included integrating materials into one resource (e.g., the course website) so they did not have to search to find materials on various platforms. As a university-wide solution was not available, professors used various online resources, and so students were forced to use multiple platforms and passwords. This is far from optimal, and so a password-free platform would alleviate any need to deal with students having difficulty accessing materials.

The requirements specification detailed the necessary functionalities in the initial version and added features in an extended version. This article discusses the initial version. 


\section{DESIGN PHASE}

Once the requirements were established, the next priority was to design a prototype course website. As this website is designed to help students learn, the pedagogy had to be considered. Each teacher who delivers this course has its own teaching philosophy, which may contain behaviorism, constructivism, and humanism. The course's theoretical underpinnings are based on the course designers' beliefs regarding language, learning, and learners. These beliefs were made explicit in a teaching philosophy statement [8]. One of the core concepts was the desire to develop learner autonomy, which can serve as a foundation for lifelong learning.

\subsection{Pedagogic Principles}

Ideally, teachers of thesis writing are specialists in both the specific content discipline and academic English [9], but this is rarely the case when language courses are delivered by a unit or center that serves a university's needs. Therefore, this course is designed for teachers and students with little or no knowledge of the genre of scientific writing in the field of computer science. A corollary of this is that computer science experts may find some of the examples and advice rather simplistic. However, this course is not designed for computer science experts but for learners who are trying to draft the best possible graduation thesis.

\subsection{Learner Autonomy}

Holec [10] defined autonomy as the "ability to take charge of one's own learning" (p.3). Benson [11] also focuses on autonomy as a capacity in which various abilities affect learning (p.290). Reinders [12] in an easier-to-operationalized definition, states that "autonomous language learning is an act of learning whereby motivated learners consciously make informed decisions about that learning" (p.48). The keywords are "informed decisions". Thus, to design a course that helps learner autonomy, the course needs to enable learners to make decisions based on sufficient information.

One way to help learners develop autonomy is to integrate learner training into the course materials. Nunan [13] designed a nine-step program for teachers to incorporate learner training into their syllabi with the aim of increasing learner autonomy. The steps are:

1. Make instruction goals clear to learners.

2. Allow learners to create their own goals.

3. Encourage learners to use their second language outside the classroom.
4. Raise awareness of learning processes

5. Help learners identify their own preferred styles and strategies.

6. Encourage learner choice

7. Allow learners to generate their own tasks.

8. Encourage learners to become teachers.

9. Encourage learners to become researchers.

Some of these steps appear straightforward and easy to implement. Step 1, for example, can be achieved by including the unit's objectives at the start of the unit. However, providing written objectives does not necessarily mean they are clear; or that students will read them, and if they read them, whether they understand them. Ideally, the students' understanding of the goals (or objectives) needs to be checked. Each of the steps is fraught with similar difficulties. Where possible, these steps were implemented.

\section{WEBSITE DESIGN}

It is common practice for website developers to use different languages for different purposes. Table 1 provides an overview of the four elements, their respective languages, and the used file extensions. In the early days of the worldwide web, simple websites were created in a hypertext markup language (HTML). However, with the advent of cascading style sheets (CSS), the styling of the content was separated out. The simplest way to style a website is to put all the instructions in one external style sheet [14].

Websites nowadays incorporate many features that increase their usability, readability, and engagement. Various actions can be automated based on user actions, such as mouse movements like hovering, entering, leaving, or clicking in particular regions of the webpage. These actions can be controlled using JavaScript. These three web scripting languages (HTML, CSS, and JavaScript) work client-side, which means that they are downloaded onto the user's computer. Whatever actions the user makes are not sent to a server but are executed within the browser.

For complex interactions that require databases, it is necessary for the webpage and a server to send and receive messages. This requires another language. PHP is the most common language used for this purpose, although other languages can be used. These languages' learning curve is steep, with PHP being particularly notorious. A key difficulty is the necessity to avoid security breaches. As the course website does not need to access a database, only the three straightforward web scripting languages were used. 
Table 1. Elements, languages and extensions

\begin{tabular}{lll}
\hline Element & Language & Extension \\
\hline Content & $\begin{array}{l}\text { Hypertext markup } \\
\text { language }\end{array}$ & HTML \\
Style & Cascading style sheet & CSS \\
Behaviour & $\begin{array}{l}\text { JavaScript } \\
\text { Interaction }\end{array}$ & $\begin{array}{l}\text { PHP: Hypertext } \\
\text { Preprocessor }\end{array}$ \\
\hline
\end{tabular}

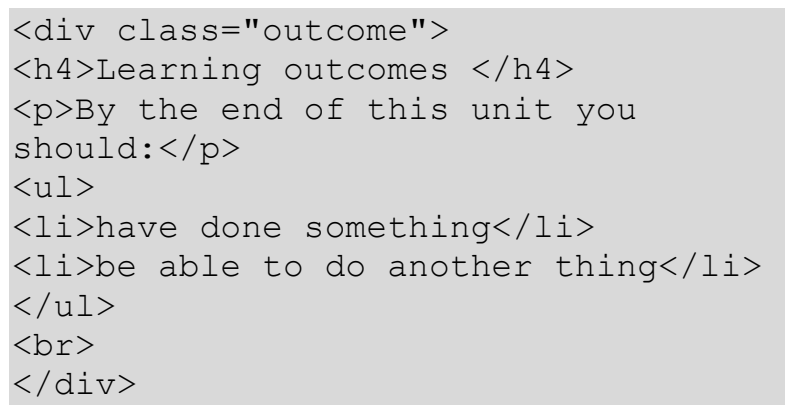

Figure 1 Excerpt of HTML code for the learning outcomes

\subsection{Content}

The content was written in a hypertext markup language (HTML). As shown in Figure 1, angular brackets are used to label each text element. This element is one division within the webpage. This division shows the learning outcomes and so is given the class "outcome". The bullet point (unordered) list is marked by $\langle\text { ul }\rangle_{\ldots} .</$ ul $\rangle$. Each item in the list marked by $\langle l i>\ldots</ l i\rangle$. The content displayed on the page is the words that occur between the two sets of angular brackets $<$ p $>$ This is displayed $<\mathrm{p}>$.

\subsection{Style}

As each element is labeled, its style, color, shape, size, etc., can easily be manipulated using CSS. This greatly simplifies the process of updating. For example, a website uses an italic font for each instruction but a normal font with a beige background color for each learning outcome. This can be controlled with just a few code lines in CSS as shown in Figure 2.

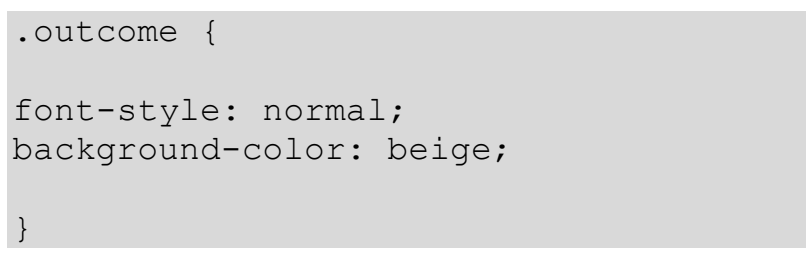

Figure 2 Excerpt of CSS for outcome class

This can be saved in an external style sheet. This means that when a div is assigned the class of outcome (as in line 1 in Figure 1), these styles will be applied by default to the whole division unless they are overwritten.

\subsection{Behaviour}

In this first online version of the thesis writing course, little use was made of behavior due to time pressure. This is a shortcoming of this course, and one that will be addressed in the updated version. JavaScript can be used to engage learners in activities. Typical language learning activities include quiz-like questions in which learners select from a choice. Their selection is evaluated as correct or incorrect, and feedback can be provided.

Creating activities using JavaScript is timeconsuming, but others' reusing activities is one way to generate materials quickly. To avoid accusations of plagiarism, it is good practice to ensure that any source is referenced. In this website, a useful JavaScript activity created by Andrew Morrall was adapted from the Hong Kong Polytechnic University CILL website.

\section{DEVELOPMENT PHASE}

With this pedagogic base, the course units' scope, focus, and objectives were decided, and then the course content was created. The first priority was to get a quick-and-dirty prototype online. This prototype served as a sandbox to test out the course website's form, format, and functionalities.

A standard template course framework was adopted comprising ten webpages, with each webpage housing the content for one unit [15] of the thesis writing and presentations course. The body of the web page for each unit is divided into sections, each consisting of one Div Object, demarcated using the angular brackets $<\operatorname{div}>\ldots</ \operatorname{div}>$.

Figure 3 shows a screenshot of the course as it would be viewed on a smartphone. Each unit is topped and tailed [16], starting with an objectives section (colored beige using the CSS external stylesheet) and finishing with a review section to show users what they should focus on and to check whether the objectives have been achieved. Emoticons, such as the yellow thinking face next to Activity 1 in Figure 3, are used to provide visual anchors. This enables learners to scroll down a webpage and understand what skills will be used and what activities should be undertaken. Instructions are italicized, while explanations and examples are in normal font. Sections in which learners are expected to read are coloured pale green and an emoticon of a pair of eyes is placed next to its corresponding heading.

In Figure 3, there are two Activity 1s. This is because some professors only use the short-version which provides a very basic introduction to using 


\section{Sources}

\section{Unit 5}

\section{Learning outcomes}

By the end of this unit you should:

- understand how to use sources

- know the difference between text recycling and plagiarism

- know the difference between quotations, paraphrases and summaries.

\section{Using sources (short version)}

This short version is enough if you just want to know how to use sources.

\section{Activity 1}

Decide the missing word for each sentence and then click "show" to check. If you do not use LaTeX, answer only questions 1 and 2.

1. When you use ideas or words that are not yours, place a ..... in square brackets, e.g. [3].

2. At the end of your graduation thesis, include the full reference in your ....

3 . In ..... use the command \cite to refer to your source.

4. The command \bibliography\{.... $\}$ refers to your BibTeX file references.bib.

5. If you do not ..... the source, the source will not show in your references when using the LaTeX default setting.

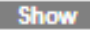

\section{Using sources (full version)}

\section{Activity 1 *}

Read.

\section{Draft 1}

The sun is very hot [1].

Reference

[1] Google result. https://www.google.co.jp/search? ei=oWDiW4XJNoKp8QWYu5PoBw\&q=temperature+of +sun+surface\&oq=temperatur ab.3..0l4joi22i30k115joi22i10i30k1.188.1535.0.1872.7.5.0.0.0.0.579.1582.23j1j0j1.5.0....0...1c.1.64.psy-ab..2.5.1577...0i10k1.0.eZj_ZhXSDnk

\section{Commentary 1}

This draft is not only very short, but very strange. Everyone reading this graduation thesis will know that the sun is hot, so there is no need for a citation. This citation is also very unclear. Citations should refer to some reliable source. Google is very powerful, but the search engine results change regularly. Any source used should be more stable, such as a journal article.

\section{Draft 2}

The sun is approximately 5800 degrees. [1].

Reference

[1] Wikipedia article: Sun. Available at: https://en.wikipedia.org/wiki/Sun

Figure 3 Screenshot of the viewport on smartphone 
Sources while other professors will select the long version and cover citations, quotations, and paraphrasing in greater detail.

A print mode function was incorporated into the CSS to enable teachers and learners to print out the web-based materials. Acknowledging the importance of affective factors, a motivational tip or feel-good quote is incorporated in the footer.

\section{EVALUATION PHASE}

The course was evaluated by three groups of stakeholders, namely the teachers, learners, and developers.

Extensive usability testing [18] was conducted to discover how learners used the website during its development and trial period. From the testing, a to-do list of improvements was created. The simple to-do tasks were implemented quickly, while others are added to the job queue and prioritized. Feedback from the students was received via end-of-course questionnaires and focus group interviews. Students' comments on the course website were positive. No students requested printed materials.

Feedback was sought from the professors delivering the course during a focus group meeting held during a formal staff meeting. The course developer was absent from encouraging faculty to speak frankly. The course website was evaluated positively by the tutors. Comments from the professors included that unlike paper-based textbooks, the online course can use hyperlinks, embedding, and user-activated behaviours, which regular internet users have come to expect. Despite the initial stated preference for printed materials, the professors who requested that functionality did not utilize that mode.

From the course developer's perspective, one advantage of a web-based course over a printed course is the ease of updating and correcting typos. Each time a typo was noticed, the website could be updated almost immediately, and when the browser refreshes, the updated version is displayed. Whereas with print editions, this ad hoc correction is impossible. Another advantage over printed matter is that external tools can be embedded into webpages and/or hyperlinks provided. Embedding provides users with an idea of what the resource looks like and depending on the functionalities, try it out via the embedded view. A genre-specific error detector [17] is one of the tools embedded in this site.

Users can find and access all the resources from a simple-to-navigate website. The final product is a userfriendly, learner-friendly website that is easy to maintain and update.

\section{CONCLUSION}

The move to digital delivery may appear onerous, but web scripting using HTML and CSS is not programming. There are no complex algorithms or data structures to learn. However, when venturing into the realm of JavaScript and PHP, the boundaries between simple web scripting and programming may blur.

The key transition for many educators will be the move away from drafting in a rich text environment, such as Microsoft Word, to writing in plain text (or at the very least saving a Word document as an HTML file by selecting the webpage filtered option from the dropdown menu).

Many websites, blogs, and video tutorials explain how to use HTML and CSS, and even more freely available templates for basic websites, so the entry barrier to creating a course website is relatively low. The payoff, however, is very high. Once a site is online, it is easy to make incremental improvements and transform a mediocre site into a fully-fledged active learning platform where learners can immerse themselves in the learning materials.

The course website described in this article is currently under revision. Future improvements include a move to a responsive website that adapts to the size of the browser more smoothly than the current adaptive website. More extensive use of behaviours controlled by JavaScript will also be incorporated to help engage users with the course materials by allowing them to interact with the site.

\section{REFERENCES}

[1] M. Mubassira, A.K. Das, The Impact of University Students' Smartphone Use and Academic Performance in Bangladesh: A Quantitative Study, in: S. Lee, R. Ismail, H. Choo (Eds.) Proceedings of the 13th International Conference on Ubiquitous Information Management and Communication, IMCOM 2019. Advances in Intelligent Systems and Computing, vol 935, 2019, Springer, Cham. DOI: https://doi.org/10.1007/978-3-030-19063$7 \quad 59$

[2] M. Tateno, D. Kim, A. Teo, N. Skokauskas, A. Guerrero, and T. Kato, Internet Addiction, Smartphone Addiction, and Hikikomori Trait in Japanese Young Adult: Social Isolation and Social Network. Psychiatry Investigation, 16(2), (2019), 115-120.

[3] L. Rosliana, A. Widiandari, Online Game and the Hikikomori Phenomenon in Japan. In E3S Web of Conferences, vol. 202, 2020, p. 07080, EDP Sciences, DOI: https://doi.org/10.1051/e3sconf/202020207080 
[4] John Hopkins University of Medicine. Coronavirus Research Center. https://coronavirus.jhu.edu/map.html

[5] John Hopkins University of Medicine. Coronavirus Research Center. https://coronavirus.jhu.edu/data/mortality

[6] E. Kaneko et al., English Curriculum Innovation for Computer Science Majors in the Japanese EFL Context: From Needs to Tasks, 2018 IEEE International Professional Communication Conference (ProComm), Toronto, ON, 2018, pp. 84-89,

DOI: https://doi.org/10.1109/ProComm.2018.00028

[7] M. Dougiamas, P. Taylor. Moodle: Using learning communities to create an open-source course management system, in: EdMedia+ Innovate Learning, 2003, pp. 171-178. Association for the Advancement of Computing in Education (AACE), https://www.learntechlib.org/p/13739/

[8] B. Coppolla, Writing a statement of teaching philosophy: Fashioning a framework for your classroom, Journal of the College of Science Teaching, 31(7), (2002), 448-53.

[9] J. Blake and W. Holden, Engaging and empowering scientific writers in different disciplines, in: B. Morrison, J. Chen, L. Lin and A. Urmston (Eds.), English Across the Curriculum: Voices from Around the World, 2021, WAC Clearinghouse / University Press of Colorado. (in press).

[10] H. Holec, Autonomy and Foreign Language Learning, 1981, Oxford: Pergamon Press.

[11] P. Benson, Learner autonomy in the classroom, in: D. Nunan, (Ed.) Practical English Language Teaching, 2003, New York: McGraw Hill.

[12] H. Reinders, From autonomy to autonomous language learning, in: A. Ahmed, G. Cane, M. Hanzala, (Eds.), Teaching English in multilingual contexts: Current challenges, future directions, 2011, pp.37-52.

[13] D. Nunan, The learner-centered curriculum, 1988, Cambridge: Cambridge University Press

[14] A.W. West, Styling the Website with CSS. In: Practical Web Design for Absolute Beginners, 2016, Apress, Berkeley, CA. DOI: https://doi.org/10.1007/978-1-4842-1993-5 3

[15] J. Blake, Asynchronous Peer Teaching Using Student-created Multimodal Materials, International Journal of Information and Education Technology, 2021, (in press).
[16] J. Blake, Sound start, firm finish, English Teaching Professional, 116, 2018, pp. 17-18.

[17] J. Blake, Genre-specific error detector with multimodal feedback, RELC Journal, 51(1), (2020) pp.179-187, DOI: https://doi.org/10.1177/0033688219898282

[18] Barnum, Carol M. Usability testing essentials: ready, set... test! ( $2^{\text {nd }}$ edition). Cambridge, MA: Morgan Kaufmann, 2020. 